\title{
Agonistic sounds in the skunk clownfish Amphiprion akallopisos: size-related variation in acoustic features
}

\author{
O. Colleye* $\dagger$, B. Frederich*, P. Vandewalle*, M. Casadevall $\dagger$ \\ AND E. PARMENTIER* \\ *Laboratoire de Morphologie Fonctionnelle et Evolutive, Département des Sciences et Gestion de \\ l'Environnement, Université de Liège, Institut de Chimie, Bât B6c, 4000 Liège, Belgium and \\ $\dagger$ Unitat de Biologia Animal, Facultat de Ciències, Universitat de Girona, Campus de Montilivi \\ s/n, 17071 Girona, Spain
}

(Received 21 October 2008, Accepted 17 April 2009)

\begin{abstract}
Fourteen individuals of the skunk clownfish Amphiprion akallopisos of different sizes and of different sexual status (non-breeder, male or female) were analysed for four acoustic features. Dominant frequency and pulse duration were highly correlated with standard length $(r=0.97)$, and were not related to sex. Both the dominant frequency and pulse duration were signals conveying information related to the size of the emitter, which implies that these sound characteristics could be useful in assessing size of conspecifics.

(c) 2009 The Authors

Journal compilation (c) 2009 The Fisheries Society of the British Isles
\end{abstract}

Key words: clownfishes; fish size; Pomacentridae; sound production.

Many teleosts have developed mechanisms allowing them to emit sounds for social communication (Ladich \& Fine, 2006; Parmentier et al., 2006a). Sounds are most frequently produced by stridulation of bony structures (Moulton, 1958; Fine et al., 1977) or result from rhythmical vibration of the swimbladder by deformation of its wall under the action of specialized sonic muscles that are attached to it (Demski et al., 1973; Connaughton et al., 2000; Parmentier et al., 2006a). Acoustic cues may provide information related to sex, mate location, readiness to spawn, body size, fighting ability, fitness and species or individual identity (Myrberg \& Riggio, 1985; Myrberg et al., 1986, 1993; Kenyon, 1994; Lobel \& Mann, 1995). Different studies on the acoustic biology of fishes have revealed that some temporal and spectral features are related to fish size: smaller individuals produce higher frequency and shorter duration sounds than larger individuals (Myrberg et al., 1993; Lobel \& Mann, 1995; Connaughton et al., 2000). Both sonic features are signals that convey information related to the size of the emitter.

The damselfishes (Pomacentridae), one of the most speciose families among coralreef fishes, are prolific callers which produce a wide variety of sounds in different kinds of behavioural contexts (Myrberg, 1972; Kenyon, 1994; Mann \& Lobel, 1998; Parmentier et al., 2006b). Within this family, clownfishes (genus Amphiprion) are

†Author to whom correspondence should be addressed. Tel.: +32 436650 33; fax: +32 436637 15; email: O.Colleye@ulg.ac.be 
territorial fishes well known to live in symbiosis with sea anemones that host them (Allen, 1972). They produce sounds during agonistic interactions involving conspecifics or heterospecifics (Allen, 1972; Parmentier et al., 2005). The agonistic sounds are mainly composed of pulses (commonly known as 'pop') which can be emitted alone or in series (Myrberg, 1972; Parmentier et al., 2006b).

Amphiprion spp. live in social groups composed of a breeding pair and between zero to four non-breeders, depending on species and size of host (Fricke, 1979; Buston, 2003). Within each group, the sex is controlled socially and there is a sizebased dominance hierarchy: the breeding female is the largest individual, the breeding male is second largest and the non-breeders get progressively smaller as the hierarchy descends. In such a system, body size ratios are well defined between each dominant and its immediate subordinate in rank (Buston, 2003). Agonistic interactions are responsible for maintaining size differences between individuals adjacent in rank within the group (Fricke, 1979; Buston, 2003). Sounds could thus play a role in the behaviour of clownfishes because they are associated with agonistic activities. The present study aims to seek if differences in sonic features exist between individuals of different sizes and of different sexual status (non-breeder, male and female) in Amphiprion akallopisos Bleeker.

Fourteen A. akallopisos (standard length, $L_{\mathrm{S}}, 28-90 \mathrm{~mm}$ ) were collected by scuba diving in the lagoon in front of Toliara (Mozambique Channel, west coast of Madagascar) (23 $\left.36^{\prime} \mathrm{S} ; 43^{\circ} 66^{\prime} \mathrm{E}\right)$ in October 2007. Fish were caught by removing carefully their anemone host [Heteractis magnifica (Quoy \& Gaimard)] from its support and by placing it in a bucket. The A. akallopisos followed their host. Host and fish were maintained in an outdoor community tank $(3.50 \times 0.7 \times 0.2 \mathrm{~m})$ filled with running sea water at a constant temperature of $26^{\circ} \mathrm{C}$.

Recordings were made in a smaller glass tank $(0.8 \times 0.35 \times 0.35 \mathrm{~m})$ at $26^{\circ} \mathrm{C}$. One A. akallopisos pair (i.e. composed of two individuals of different sizes) and its host were placed in the centre of the tank for an acclimation time (c. 1 day). The experimental pair was then challenged by introduction of conspecific intruders into the tank, a well-known technique to evoke aggressive territorial displays and acoustic behaviours by both fish of the resident pair (Parmentier et al., 2005). Sounds were produced when the intruders entered the territory (the sea anemone) defended by the resident pair. This territorial behaviour was accompanied by typical movements of sound production (i.e. rapid jaws closure; Parmentier et al., 2007), which enabled the sound emitter to be identified. Recordings lasted for c. $30 \mathrm{~min}$, after which the intruders were removed and replaced in the community tank until the following session.

After sounds had been recorded for all specimens, fish were killed with an overdose of tricaine methanesulphonate (MS-222) in solution. Gonads were removed and placed in a Bouin's fixative solution for the production of serial histological sections.

Sound recordings were made using an Orca hydrophone (sensitivity: $-186 \mathrm{~dB}$ re $1 \mathrm{~V} / \mu \mathrm{Pa}$ ) connected via an Orca-made amplifier (Orca Instrumentation; www.orcainst.com) to a Tascam HD-P2 stereo audio recorder (recording bandwidth: $20 \mathrm{~Hz}$ to $20 \mathrm{kHz} \pm 1.0 \mathrm{~dB}$; www.tascam.com). This system has a flat frequency response range $( \pm 3 \mathrm{~dB})$ between 10.0 and $23.8 \mathrm{kHz}$. The hydrophone was placed just above the sea anemone $( \pm 10 \mathrm{~cm})$.

Each pulse unit was digitized at $44.1 \mathrm{kHz}$ (16 bit resolution) and analysed with AviSoft-SAS Lab Pro 4.33 software [1024 point Hanning windowed fast Fourier 
transform (FFT); www.avisoft.com]. Recording in small tanks induces potential hazards because of reflections and tank resonance (Akamatsu et al., 2002). The resonant frequency of the tank was determined as $3.17 \mathrm{kHz}$ using a relevant equation from Akamatsu et al. (2002), and a low pass filter of $3.17 \mathrm{kHz}$ was applied to all sound recordings. Temporal features were measured from the oscillograms and frequency variables were obtained from power spectra (filter bandwidth $300 \mathrm{~Hz}$, FFT size point 256, time overlap $96.87 \%$ and a flat top window). Aggressive sounds are composed of a train of pulses. The following features were measured: number of pulses in a series, pulse duration (i.e. the time interval between the onset of one pulse and its end), pulse period (measured as the average peak to peak interval between consecutive pulse units in a series) and dominant frequency in $\mathrm{Hz}$ (Fig. 1).

Gonadal histological examination was undertaken to attest the sex of each individual. After fixation in a Bouin's solution for c. 30 days, gonads were dehydrated with ethanol, embedded in paraffin wax (Paraplast ${ }^{\circledR}$ brand) and serial cut with a Reichert microtome (www.leica-microsystem.com). The serial cross-sections $(8 \mu \mathrm{m})$ were stained using Masson's trichrome method (Ganter \& Jolles, 1970) and were examined under a Leica DM1000 microscope (www.leica-microsystem.com). The gonads were categorized according to the study of Hattori \& Yanagisawa (1991) and Casadevall et al. (2009). Among the collected fish, there were 12 breeders (six females and six males) and two non-breeders.

Correlation analyses were used to examine changes in all acoustic characteristics across $L_{S}$. The data used in these analyses were mean values of all recorded pulses for each individual. Two statistical analyses were then performed to test the influence of sex on sonic features. First, a full ANCOVA was run to determine differences between males and females for the sonic variables correlated with $L_{S}$. Non-breeders were not included in this statistical test due to the small sample size (only two individuals). In this test, sonic variables are considered as variates, $L_{\mathrm{S}}$ as a covariate and sex is the grouping factor. Secondly, sonic variables not correlated with $L_{S}$, which failed the test for normal distributions (Kolmogorov-Smirnov test), were analysed using a non-parametric Kruskal-Wallis one-way ANOVA by ranks with subsequent Dunn's test for pair-wise comparisons to test differences between sexes (non-breeders, males and females). Results are presented as means \pm S.D. Significance was determined at $P<0.05$.

Agonistic sounds ( $n=1818$ pulses analysed; Table I) were produced by individuals of the different sexual status which displayed charge-and-chase when another specimen approached the sea anemone in which they dwelled.

Correlation analyses revealed that dominant frequency and pulse duration were highly correlated with $L_{S}$. The most striking changes were a significant decrease in dominant frequency $[r=-0.97, P<0.001$; Fig. 2(a) $]$ and a significant increase in pulse duration $\left[r=0.97, P<0.001\right.$; Fig. 2(b)] with increasing $L_{\mathrm{S}}$. Pulse period was correlated with increasing $L_{\mathrm{S}}[r=0.62, P=0.01$; Fig. 2(c) $]$ but this correlation needs to be carefully interpreted because this sonic variable is also correlated with pulse duration $(r=0 \cdot 66, P=0 \cdot 01)$. The number of pulses per train did not change significantly $[r=0.06, P=0.82$; Fig. $2(d)]$ across $L_{\mathrm{S}}$.

A comparison of male and female values using $L_{\mathrm{S}}$ as a covariate showed that the dominant frequency (ANCOVA, test for common slopes: $F_{1,8}, P>0 \cdot 05$; test for intercepts: $F_{1,9}, P>0.05$ ) and pulse duration (ANCOVA, test for common slopes: 

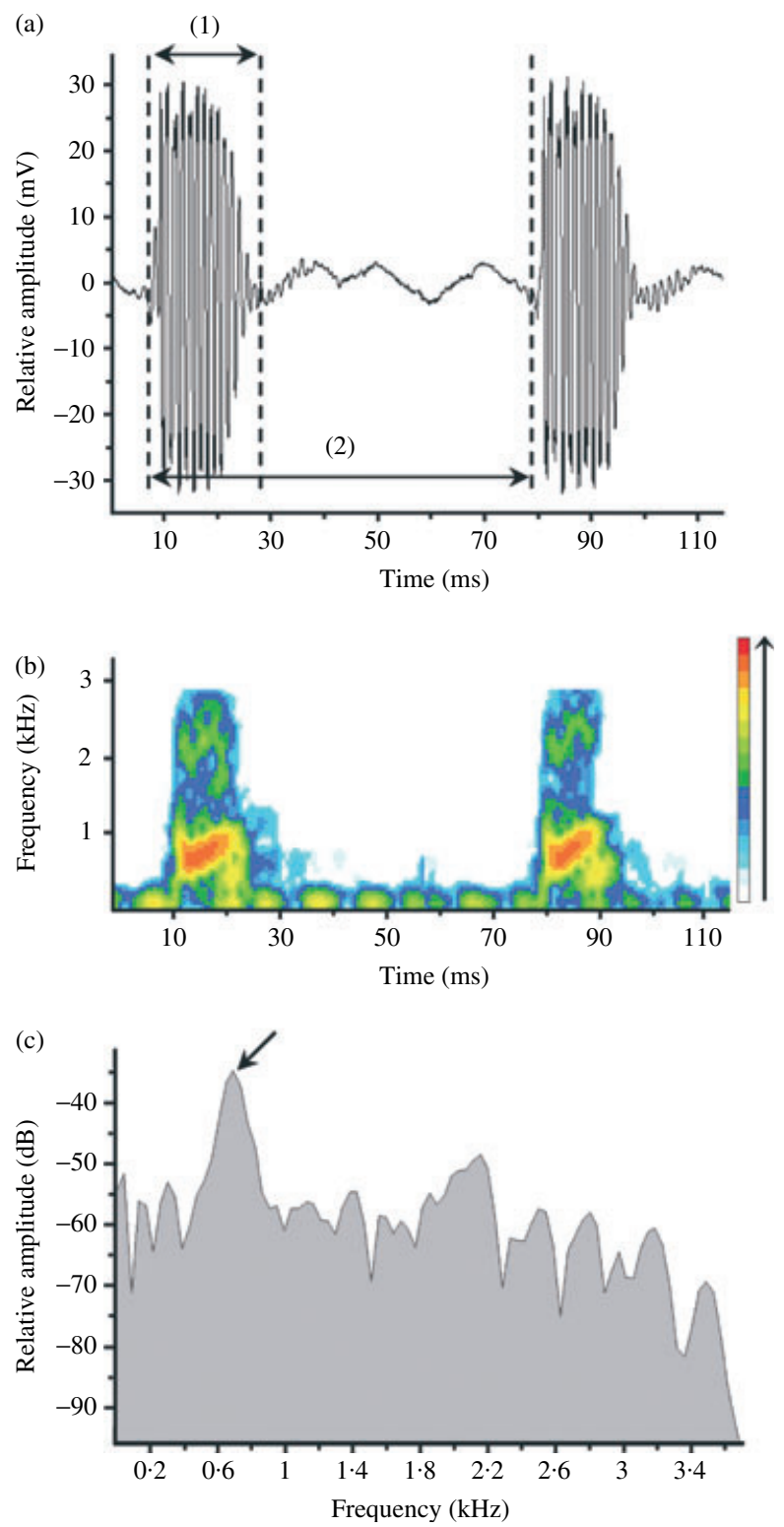

FIG. 1. (a) Oscillogram and (b) sonogram of agonistic sounds produced by Amphiprion akallopisos. Sonic variables measured in the signal: (1) pulse duration, (2) pulse period. The colour scale corresponds to the intensity associated with the different frequencies. (c) Power spectrum of one pulse showing the dominant frequency $(\rightarrow)$.

$F_{1,8}, P>0 \cdot 05$; test for intercepts: $\left.F_{1,9}, P>0.05\right)$ did not differ between males and females.

Kruskal-Wallis one-way ANOVA revealed that means were significantly different between sexes for pulse period $(H=6 \cdot 305$, d.f. $=2, P=0.0428)$, but not for number of pulses per train due to considerable overlap $(H=1.559$, d.f. $=2$, 
TABLE I. Summary (mean \pm S.D.) of the four acoustic features analysed from 14 Amphiprion akallopisos

\begin{tabular}{|c|c|c|c|c|}
\hline & $\begin{array}{c}\text { Pulse } \\
\text { duration (ms) }\end{array}$ & $\begin{array}{c}\text { Dominant } \\
\text { frequency }(\mathrm{Hz})\end{array}$ & $\begin{array}{c}\text { Pulse } \\
\text { period (ms) }\end{array}$ & $\begin{array}{c}\text { Number of pulses } \\
\text { per train }\end{array}$ \\
\hline Individual $(n)$ & Mean \pm s.D. & Mean \pm s.D. & Mean \pm S.D. & Mean \pm s.D. \\
\hline Non-breeders (2) & $6 \cdot 7 \pm 1 \cdot 1$ & $988 \pm 33$ & $72 \cdot 4 \pm 0 \cdot 3$ & $3 \cdot 6 \pm 0 \cdot 3$ \\
\hline Males (6) & $11 \cdot 3 \pm 2 \cdot 0$ & $776 \pm 116$ & $71 \cdot 7 \pm 4 \cdot 2$ & $4 \cdot 1 \pm 0.6$ \\
\hline Females (6) & $16 \cdot 2 \pm 2 \cdot 8$ & $505 \pm 91$ & $81 \cdot 2 \pm 7 \cdot 2$ & $3.6 \pm 0.7$ \\
\hline
\end{tabular}

$P=0.4586)$. Pair-wise comparisons showed that pulse periods were higher in females (Dunn's test, $P<0.05$; Table I) than in both males and non-breeders, which showed no significant differences between them (Dunn's test, $P>0.05$; Table I).

Some evidences attest that dominant frequency and pulse duration are related to fish size in the A. akallopisos: larger individuals produce lower frequency and longer duration pulses than smaller individuals. In the croaking gourami Trichopsis vittata (Cuvier) for example, sound duration increases during ontogeny whereas dominant frequency decreases (Henglmüller \& Ladich, 1999). In the grey gurnard Eutrigla gurnardus (L.), sound production changes from small juveniles to large adults during competitive feeding (Amorim \& Hawkins, 2005). In catfishes (Siluriformes) (Fine \& Ladich, 2003), weakfishes (Sciaenidae) (Connaughton et al., 2000), damselfishes (Pomacentridae) (Myrberg et al., 1993; Lobel \& Mann, 1995), gouramis (Osphronemidae) (Ladich et al., 1992) and pearlfishes (Carapidae) (Parmentier et al., 2006a), pulse duration increases and dominant frequency decreases in larger fishes. The same kind of relationship has been observed in A. akallopisos in which differences in both sound characteristics are related to fish size, and not to sexual status. Size and sex are, however, extremely dependent on each other due to the existing size dimorphism between males and females (Allen, 1972). Besides carrying information related to the size, dominant frequency and pulse duration could therefore be signals conveying information on the identity of the emitter.

Within each group, a well-defined size difference is maintained between individuals adjacent in rank (Fricke, 1979; Buston, 2003) Aggressive displays are responsible for maintaining size differences within the hierarchy (Fricke, 1979; Buston, 2003), avoiding the generation of evolutionary conflict over subordinates who would become a threat to their dominants by challenging them for their rank (Buston, 2003). Sounds are associated with agonistic interactions (Allen, 1972; Parmentier et al., 2005), they could therefore play a role in the group by conveying a signal for allowing fish size assessment and, besides, giving a potential reminder signal of social rank during interactions. Since dominant frequency and pulse duration are size-dependent, temporal and spectral differences are likely to be detected by members within the group.

Teleosts such as Gobius niger L. and Sparus annularis (L.) are able to discriminate tonal sounds differing in frequency of $c .10 \%$; the frequency discrimination ability at $400 \mathrm{~Hz}$ is c. $40 \mathrm{~Hz}$ (Fay, 1988). In A. akallopisos, sounds emitted by nonbreeders, males and females differ in dominant frequencies by $>10 \%$ (Table I). Such a capacity to discriminate frequency differences has already been underlined in damselfish. In Abudefduf saxatilis (L.), all fish are most sensitive to the lower frequencies $(100-400 \mathrm{~Hz})$ but the frequency range detected appears to be function 


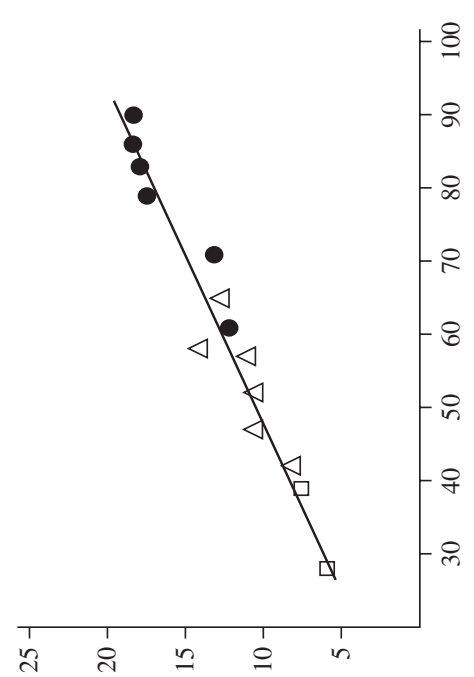

อ (su) uo!̣e.Inp әs[n

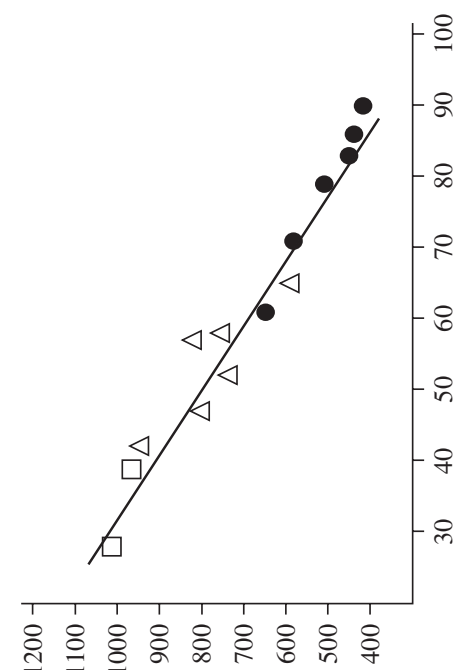

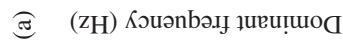

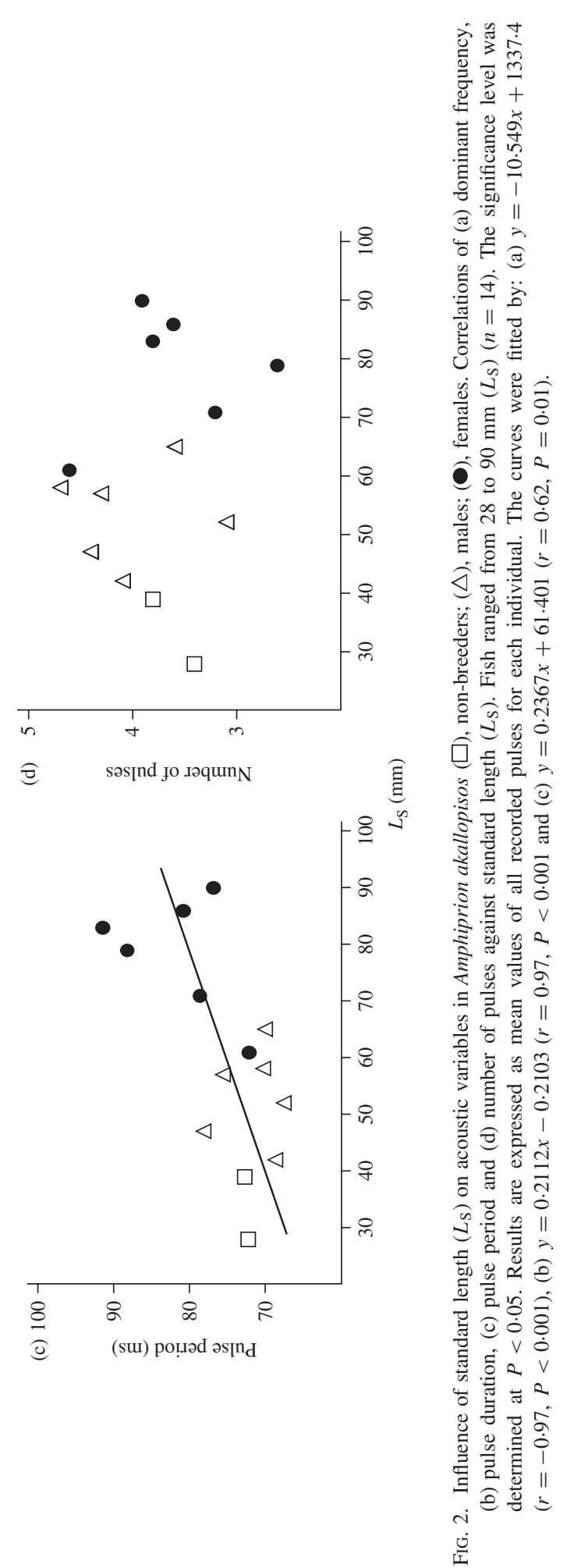


of fish size, and larger fish are more likely to respond to higher frequencies (1000-1600 Hz; Egner \& Mann, 2005).

Moreover, behavioural experiments have shown that fishes are able to respond selectively to sounds differing in their temporal pattern. Some sunfishes of the genus Lepomis could recognize conspecific grunts based on their temporal structure (Gerald, 1971). There is also evidence from further behavioural experiments that Pomacentrids would be able to distinguish temporal differences of sounds between at least 5 and $10 \mathrm{~ms}$ (Myrberg et al., 1978). Although differences in pulse duration are somewhat low among group members in A. akallopisos (Table I), it is likely they could detect them based on hearing discrimination abilities.

No information related to size can be extracted from pulse period and number of pulses per train. Differences in pulse periods have been observed between females and both males and non-breeders, which may reflect a difference in motivation. In Dascyllus albisella Gill, for example, aggressive sounds are different according to whether they are emitted towards conspecifics or heterospecifics, being multiplepulsed or single-pulsed, respectively (Mann \& Lobel, 1998). In A. akallopisos, the most aggressive males were characterized by a higher number of pulses per train and a shorter pulse period (pers. obs.). Such variations might be related to the willingness to defend the position (rank) against intruders within the sea anemone.

The present study demonstrates that dominant frequency and pulse duration are morphologically determined signals related to fish size. This relationship is of significant importance because clownfishes live in social group that display a sizebased dominance hierarchy. Both acoustic variables convey information on the size of the emitter. Presently, new behavioural tests need to be run to determine how important agonistic sounds are within the group.

The authors would like to thank J. M. Ouin and his Aqua-Lab team (Institut Halieutique et des Sciences Marines, University of Tuléar) for helping to collect fishes, and for providing hospitality and laboratory facilities. N. Decloux kindly helped in the microscopic study. This study was supported by grant FRFC (no 2.4.583.05.F). O. C. is supported by a grant from the Belgian National Fund for Scientific Research (Bourse de Doctorat F.R.S.-FNRS). E. P. is a research associate of the F.R.S.-FNRS.

\section{References}

Akamatsu, T., Okumura, T., Novarini, N. \& Yan, H. Y. (2002). Empirical refinements applicable to the recording of fish sounds in small tanks. Journal of the Acoustical Society of America 112, 3073-3082. doi: 10.1121/1.1515799

Allen, G. R. (1972). The Anemonefishes: Their Classification and Biology. Neptune City, NJ: T.F.H. Publications.

Amorim, M. C. P. \& Hawkins, A. D. (2005). Ontogeny of acoustic and feeding behaviour in the grey gurnard, Eutrigla gurnardus. Ethology 111, 255-269. doi: 10.1111/j.14390310.2004.01061.x

Buston, P. M. (2003). Size and growth modification in clownfish. Nature 424, 145-146. doi: $10.1038 / 424145 \mathrm{a}$

Casadevall, M., Delgado, E., Colleye, O., Ber Monserrat, S. \& Parmentier, E. (2009). Histological study of the sex-change in the skunk clownfish Amphiprion akallopisos. Open Fish Science Journal 2, 55-58.

Connaughton, M. A., Taylor, M. H. \& Fine, M. L. (2000). Effects of fish size and temperature on weakfish disturbance calls: implications for the mechanism of sound generation. Journal of Experimental Biology 203, 1503-1512. 
Demski, L. S., Gerald, J. W. \& Popper, A. N. (1973). Central and peripheral mechanisms of teleost sound production. American Zoologist 13, 1141-1167.

Egner, S. A. \& Mann, D. A. (2005). Auditory sensitivity of sergeant major damselfish Abudefduf saxatilis from post-settlement juvenile to adult. Marine Ecology-Progress Series 285, 213-222. doi: 10.3354/meps285213

Fay, R. R. (1988). Hearing in Vertebrates, A Psychophysics Databook. Winnetka, IL: Hill-Fay Associates.

Fine, M. L. \& Ladich, F. (2003). Sound production, spine locking, and related adaptations. In Catfishes, Vol. I (Arratia, G., Kapoor, B. G., Chardon, M. \& Diogo, R., eds), pp. 249-290. Enfield, NH: Science Publishers.

Fine, M. L., Winn, H. E. \& Olla, B. L. (1977). Communication in fishes. In How Animals Communicate (Sebeok, T. A., ed.), pp. 472-518. Bloomington, IN: Indiana University Press.

Fricke, H. W. (1979). Mating system, resource defense and sex change in the anemonefish Amphiprion akallopisos. Zeitschrift für Tierpsychologie 50, 313-326.

Ganter, P. \& Jolles, G. (1970). Histochimie Normale et Pathologique. Paris: Gauthier-Villars.

Gerald, J. W. (1971). Sound production in six species of sunfish (Centrarchidae). Evolution 25, 75-87.

Hattori, A. \& Yanagisawa, Y. (1991). Life-history pathways in relation to gonadal sex differentiation in the anemonefish, Amphiprion clarkii, in temperate waters of Japan. Environmental Biology of Fishes 31, 139-155. doi: 10.1007/BF00001015

Henglmüller, S. M. \& Ladich, F. (1999). Development of agonistic behaviour and vocalization in croaking gouramis. Journal of Fish Biology 54, 380-395. doi: 10.1111/j.10958649.1999.tb00837.x

Kenyon, T. N. (1994). The significance of sound interception to males of the bicolor damselfish, Pomacentrus partitus, during courtship. Environmental Biology of Fishes 40, 391-405. doi: 10.1007/BF00005282

Ladich, F. \& Fine, M. L. (2006). Sound generating mechanisms in fishes: a unique diversity in vertebrates. In Communication in Fishes (Ladich, F., Collin, S. P., Moller, P. \& Kapoor, B. G., eds), pp. 1-43. Enfield, NH: Science Publishers.

Ladich, F., Bischof, C., Schleinzer, G. \& Fuchs, A. (1992). Intra- and interspecifics differences in agonistic vocalization in croaking gouramis (genus: Trichopsis, Anabantoidei, Teleostei). Bioacoustics 4, 131-141.

Lobel, P. S. \& Mann, D. A. (1995). Spawning sounds of the damselfish, Dascyllus albisella (Pomacentridae), and relationship to male size. Bioacoustics 6, 187-198.

Mann, D. A. \& Lobel, P. S. (1998). Acoustic behavior of the damselfish Dascyllus albisella: behavioral and geographic variation. Environmental Biology of Fishes 51, 421-428. doi: 10.1023/A:1007410429942

Moulton, J. M. (1958). The acoustical behavior of some fishes in the Bimini area. Biological Bulletin 114, 357-374.

Myrberg, A. A. (1972). Ethology of the bicolour damselfish Eupomacentrus partitus (Pisces: Pomacentridae): a comparative analysis of laboratory and field behaviour. Animal Behavior Monographs 5, 197-283.

Myrberg, A. A. \& Riggio, R. J. (1985). Acoustically mediated individual recognition by a coral reef fish (Pomacentrus partitus). Animal Behavior 33, 411-416. doi: 10.1016/S0003-3472(85)80065-8

Myrberg, A. A., Ha, S. J. \& Shamblott, M. J. (1993). The sounds of bicolor damselfish (Pomacentrus partitus): predictors of body size and a spectral basis for individual recognition and assessment. Journal of the Acoustical Society of America 94, 3067-3070. doi: 10.1121/1.407267

Myrberg, A. A., Mohler, M. \& Catala, J. (1986). Sound production by males of coral reef fish (Pomacentrus partitus): its significance to females. Animal Behavior 34, 913-923.

Myrberg, A. A., Spanier, E. \& Ha, S. J. (1978). Temporal patterning in acoustic communication. In Contrasts in Behaviour (Reese, E. S. \& Lighter, F. J., eds), pp. 137-179. New York, NY: John Wiley \& Sons. 
Parmentier, E., Lagardère, J. P., Vandewalle, P. \& Fine, M. L. (2005). Geographical variation in sound production in the anemonefish Amphiprion akallopisos. Proceedings of the Royal Society B 272, 1697-1703. doi: 10.1098/rspb.2005.3146

Parmentier, E., Lagardère, J. P., Braquegnier, J. B., Vandewalle, P. \& Fine, M. L. (2006a). Sound production mechanism in a carapid fish: first example with a slow sonic muscle. Journal of Experimental Biology 209, 2952-2960. doi: 10.1242/jeb.02350

Parmentier, E., Vandewalle, P., Frédérich, B. \& Fine, M. L. (2006b). Sound production in two species of damselfishes (Pomacentridae): Plectroglyphidodon lacrymatus and Dascyllus aruanus. Journal of Fish Biology 68, 1-13. doi: 10.1111/j.1095-8649.2006.01117.x

Parmentier, E., Colleye, O., Fine, M. L., Frédérich, B., Vandewalle, P. \& Herrel, A. (2007). Sound production in the clownfish Amphiprion clarkii. Science 316, 1006. doi: $10.1126 /$ science. 1139753 